\title{
PERCEPTION OF HEALTH RISK AND COMPLIANCE WITH PREVENTIVE MEASURES RELATED TO COVID-19 IN THE CZECH POPULATION: PRELIMINARY RESULTS OF A RAPID QUESTIONNAIRE SURVEY
}

\author{
ANDREA DALECKÁ ${ }^{1,2}$, HANA ŠLACHTOVÁ ${ }^{1,2,3}$, HANA TOMÁŠKOVÁ ${ }^{1,2,3}$, and RASTISLAV MAD’AR ${ }^{1}$ \\ ${ }^{1}$ University of Ostrava, Ostrava, Czech Republic \\ Department of Epidemiology and Public Health \\ ${ }^{2}$ University of Ostrava, Ostrava, Czech Republic \\ Centre for Epidemiological Research \\ ${ }^{3}$ Institute of Public Health, Ostrava, Czech Republic
}

\begin{abstract}
Objectives: In the Czech Republic, an outbreak of the coronavirus disease (COVID-19) has been decelerated by quickly adopting strict and strongly limiting government measures. In this study, the authors present the preliminary results (April 1-5, 2020) of a public risk perception study of COVID-19. Material and Methods: The online questionnaire survey was announced in the national TV and radio stations with the nationwide coverage. Respondents were recruited through the website of the University of Ostrava during the first 5 days of the survey $(\mathrm{N}=7966)$. The data covered risk perception with a focus on physical and psychological aspects, the current socio-economic situation and adaptation to the lockdown. The authors used Mann-Whitney and Kruskal-Wallis tests, as well as ordered logistic regression, with a significance level of 5\% using STATA version 15. Results: From the total sample of the respondents aged 40 years on average (a range of 15-87 years), the present study shows that women ( $p<0.001$ ) and elderly people $(\mathrm{p}<0.001)$ perceived the health risk related to COVID-19 as significantly worse than others. Older people ( $>60$ years) perceived their mental health as significantly better than younger participants $(\mathrm{p}<0.001)$. Most of the respondents assessed the adopted measures as adequate $(71 \%)$ and believed in their effectiveness (69.7\%). Conclusions: This study contributes to understanding the risk perception as a public response to the COVID-19 pandemic. Int J Occup Med Environ Health. 2021;34(2):165-76
\end{abstract}

Key words:

mental health, questionnaire survey, risk communication, preventive measures, COVID-19, health risk perception

\section{INTRODUCTION}

An outbreak of the novel coronavirus disease (COVID-19) has posed an unprecedented health and socio-economic threat, which is faced by all countries around the world [1]. Generally, COVID-19 is an infectious disease caused by the SARS-CoV-2 virus (previously provisionally referred to as the 2019 novel coronavirus or 2019-nCoV), which was unknown before the outbreak began in December 2019 in Wuhan, China [2]. A number of recent studies have investigated the scale of short-term and long-term

Received: October 7, 2020. Accepted: December 22, 2020.

Corresponding author: Andrea Dalecká, University of Ostrava, Department of Epidemiology and Public Heath, Syllabova 19, 703 00 Ostrava, Czech Republic (e-mail: andrea.dalecka@osu.cz). 
health impacts of the COVID-19 disease, ranging from common cold to more severe consequences [3]. Currently, controlling the infection to prevent the spread of SARS-CoV-2 relates to the monitoring of new cases as well as a primary intervention [4]. Due to no vaccine being available, the unrestrained spread of the disease was initially decelerated by adopting strict government restrictions as well as implementing personal protection practices to avoid exposure to the virus [5,6]. Besides globally respected general measures, such as maintaining social distances, a stay-at-home order or imposing travel restrictions, the Czech Republic government established even stricter and long-lasting restrictions in comparison to most western European countries. For instance, wearing a face mask has been obligatory since March 12, 2020, and this personal protection is still ongoing. Moreover, a widespread lockdown and several other restrictions (the cancelling of weddings, no admission of fathers at childbirth, etc.) were announced and remained valid for several weeks.

The element playing the key role in achieving the successful pandemic management is the public risk perception which is understood as the people's intuitive and subjective evaluation of hazards. Risk perception of the pandemic is a crucial contributor to public adaptation to the imposed measures [7]. Perceived risks and the willingness to accept restrictions are extensively influenced by multiple socio-economic and individual factors, as well as by personal values or cultural aspects. Previous studies focusing on the perception of infectious disease risks (especially the swine-origin influenza and SARS) show that being older, female and more educated is associated with a higher possibility of adapting to the measures $[8,9]$.

According to the protection motivation theory, the evaluation of threats consists of an appraisal of the perceived vulnerability (or susceptibility) and an appraisal of the perceived severity [10]. There is growing evidence that a greater perceived susceptibility is associated with avoid- ing behavior, such as evading restaurants, public places, public events and people traveling from higher-risk countries [11]. Individuals with greater perception are more likely to report an intention to comply with quarantine restrictions [12] and to pay greater attention to personal hygiene standards [13-15]. Based on the limited results of the current studies, there are growing concerns that the perceived vulnerability and severity associated with individual behavior during the lockdown can significantly affect the psychological and mental well-being across society $[16,17]$.

It is important to note that the public risk perception of the disease is significantly conditioned by public trust. Trust is presumed by an imperfect knowledge about a given risk and the presence of the risk itself. At this conceptual level, the act of trusting is equivalent to the willingness to take a risk and to adopt precautionary measures in general [18]. The critical factor contributing to effective crisis communication is, therefore, a necessity to provide appropriate information about the pandemic by the government and public health authorities, and also to build confidence in knowledge. Hiding or downplaying the reality about risks and vulnerabilities results in reducing public trust [7]. In this study, the authors present an initial assessment of the public risk perception of COVID-19 from the Czech Republic at the beginning of the pandemic. The main goal of the work was to study the physical and psychological aspects of precautionary measures, as well as to evaluate people's trust in their effectiveness. Furthermore, the willingness to adapt to the restrictions in the Czech population was observed over time, especially with regard to the current occupational and socio-economic situation.

\section{MATERIAL AND METHODS}

The population risk perception during the period of the outbreak was assessed using a questionnaire survey that was launched almost at the beginning of the lockdown in the Czech Republic, namely on April 1, 2020. Whereas 
the results presented here were collected during the first 5 days of the survey, the survey was going on throughout the period of the outbreak to explore the risk perception development. The online questionnaire survey was announced in the national TV and radio stations with the nationwide coverage. Therefore, people from all Czech regions could be engaged in the survey. Respondents were recruited through the website of the University of Ostrava where the link to the online questionnaire was available during the entire emergency time. The ethical approval was not required for this type of the study, as the online survey was fully anonymous. Moreover, no personal data (such as the name, home address, e-mail address, date of birth etc.) were collected and no personal contact with the participants was conducted. No age, gender or socioeconomic stratification quotas were applied.

The questionnaire consisted of 5 short parts. The first part focused on the actual respondent's situation related to the SARS-CoV-2 infection (e.g., contacts with an infected person, testing results etc.). The second part consisted of several questions regarding health risk perception of COVID-19 as well as the evaluation of the current concerns about physical and mental health. The third part included questions related to the estimated present and future impacts on occupational, economic, educational and other issues. The last part focused on the trust in and willingness to comply with the lockdown and obligatory hygiene and social measures. Basic demographic variables considered as the potential confounders of risk perception were also incorporated into the questionnaire. In total, the questionnaire contained 27 questions, and its completion took approx. $10 \mathrm{~min}$.

Most questions were evaluated as average values on a 5-point Likert scale. The differences were tested by Mann-Whitney and Kruskal-Wallis tests with the significance level of $5 \%$. The ordered logistic regression was used to analyze the factors (gender, age, education, marital status, increased work demands and decreased person- al income) influencing individual health concern, mental health, and the efficiency and sufficiency of restrictions. The results were expressed as crude and adjusted odds ratios (ORs) with the $95 \%$ confidence intervals (CIs). Full models were adjusted for all the independent variables tested (age, education, marital status, increased work demands and decreased personal income). Data were analyzed using SW STATA v. 15.

\section{RESULTS}

During the first 5 days of the survey (April 1-5, 2020) 7966 questionnaires were collected via the University of Ostrava website. Predominantly women (76.6\%), younger people aged $<45$ years $(64.8 \%)$ and people with university education $(53.8 \%)$ participated in the study. Only 231 people $(2.9 \%)$ underwent the required quarantine, $71.3 \%$ of them due to the return from countries with a high COVID-19 risk and the rest due to contact with a positively tested person. Out of the 152 people tested for SARS-CoV-2 in the whole sample, only 11 received positive results of the test.

The most endangered groups in terms of the COVID-19 infection were found to include seniors aged $>80$ years and people with self-reported impaired health. Most of them fully or partly respected the restrictions like wearing a face mask (95\%), frequent hand hygiene (92\%), or spending time with $\leq 2$ people in public places $(88 \%)$. Isolation from one's family and friends (96\%) and limitation of leisure activities (95\%) were perceived as the most limitative personal impacts of the restrictions, while testing for COVID-19 (90\%), frequent hand hygiene (89\%), border lockdown (80\%), wearing a face mask (76\%) and maintaining a 2-meter distance between persons (76\%) were viewed as the most effective precautionary measures. In terms of future views, people expected a negative impact of the pandemic in the sphere of economic loss (92\%), high unemployment (66\%), and travelling behavior $(48 \%)$. 
Table 1. The distribution of health concern, affected mental health, and the sufficiency and efficiency of restrictions, using the Likert scale, among the Czech population on April 1-5, 2020

\begin{tabular}{|c|c|c|c|c|c|c|c|c|}
\hline \multirow{3}{*}{ Likert scale } & \multicolumn{8}{|c|}{$\begin{array}{l}\text { Participants } \\
(\mathrm{N}=7955)\end{array}$} \\
\hline & \multicolumn{2}{|c|}{ individual health concern $^{\mathrm{a}}$} & \multicolumn{2}{|c|}{ affected mental health ${ }^{\mathrm{b}}$} & \multicolumn{2}{|c|}{ sufficiency of restrictions ${ }^{c}$} & \multicolumn{2}{|c|}{ efficiency of restrictions } \\
\hline & $\mathrm{n}$ & $\%$ & $\mathrm{n}$ & $\%$ & $\mathrm{n}$ & $\%$ & $\mathrm{n}$ & $\%$ \\
\hline 1 & 1004 & 12.6 & 1561 & 19.6 & 484 & 6.1 & 1613 & 20.4 \\
\hline 2 & 2533 & 31.8 & 2589 & 32.6 & 1127 & 14.2 & 3887 & 49.3 \\
\hline 3 & 2785 & 35.0 & 2497 & 31.4 & 5622 & 71.0 & 2022 & 25.6 \\
\hline 4 & 997 & 12.5 & 960 & 12.1 & 511 & 6.5 & 285 & 3.6 \\
\hline 5 & 636 & 8.0 & 344 & 4.3 & 178 & 2.3 & 84 & 1.1 \\
\hline Total & 7955 & 100 & 7951 & 100 & 7922 & 100 & 7891 & 100 \\
\hline
\end{tabular}

a 1 - not worried at all to 5 - very worried; ${ }^{\mathrm{b}} 1$ - very good to 5 - very bad; ${ }^{\mathrm{c}} 1$ - excessive to 5 - insufficient; ${ }^{\mathrm{d}} 1$ - most effective to 5 - least effective.

The main research questions were focused on the identification of individual health concern and psychological impacts of the pandemic, and subsequently on testing the significance of individual and socio-economic variables in risk perception. Furthermore, people's trust in the efficiency and sufficiency of restrictions was evaluated with regard to socio-economic differences (Table 1).

Gender, age, education, marital status, decreased personal income during the pandemic and increased work demands related to performing a frontline profession were the socio-economic variables of interest that determined the actual risk perception (Table 2).

The overall individual health concern related to COVID-19, measured on a 5-point scale (1 - not worried at all, 5 - very worried), reached the mean value of 2.71 pts. (Tables 1 and 3); therefore, it may be considered that people tended not to worry about their health too much. A higher health concern was observed in people performing frontline professions, people with no personal income decrease, females, the oldest age group ( $>60$ years) and people in marriage or partnership (Table 2).

Psychological impacts (Tables 1 and 3) of the pandemic were also evaluated on a 5-point scale (1 - very good, 5 very bad), with the mean value of 2.49 pts in the whole sample. A negative psychological impact was perceived as significantly more serious in people with decreased income, females, the youngest age group (15-29 years), low-educated people, and singles, divorced or widowed people. Surprisingly, with increasing age, the level of the subjectively perceived psychological impact of the pandemic was decreasing (Table 2).

The mean sufficiency of the restrictions, measured on a 5-point Likert scale (1 - excessive, 5 - insufficient), reached 2.84 pts (Tables 1 and 3), which means that most of the participants $(71.0 \%)$ evaluated the restrictions as adequate. The perception was significantly affected by all socio-economic factors. A significant decline towards insufficiency of the restrictions was confirmed in people performing frontline professions, females, the youngest and oldest age groups, low-educated people, married respondents and people whose income was not affected by the pandemic (Table 2).

The preventive measures were evaluated as effective on a 5-point scale (1 - most effective, 5 - least effective), with the mean value of 2.16 pts (Tables 1 and 3 ). Frequent hand hygiene, border lockdown and COVID-19 testing were perceived as the most effective measures. Significantly lower reliance was found in people whose income de- 


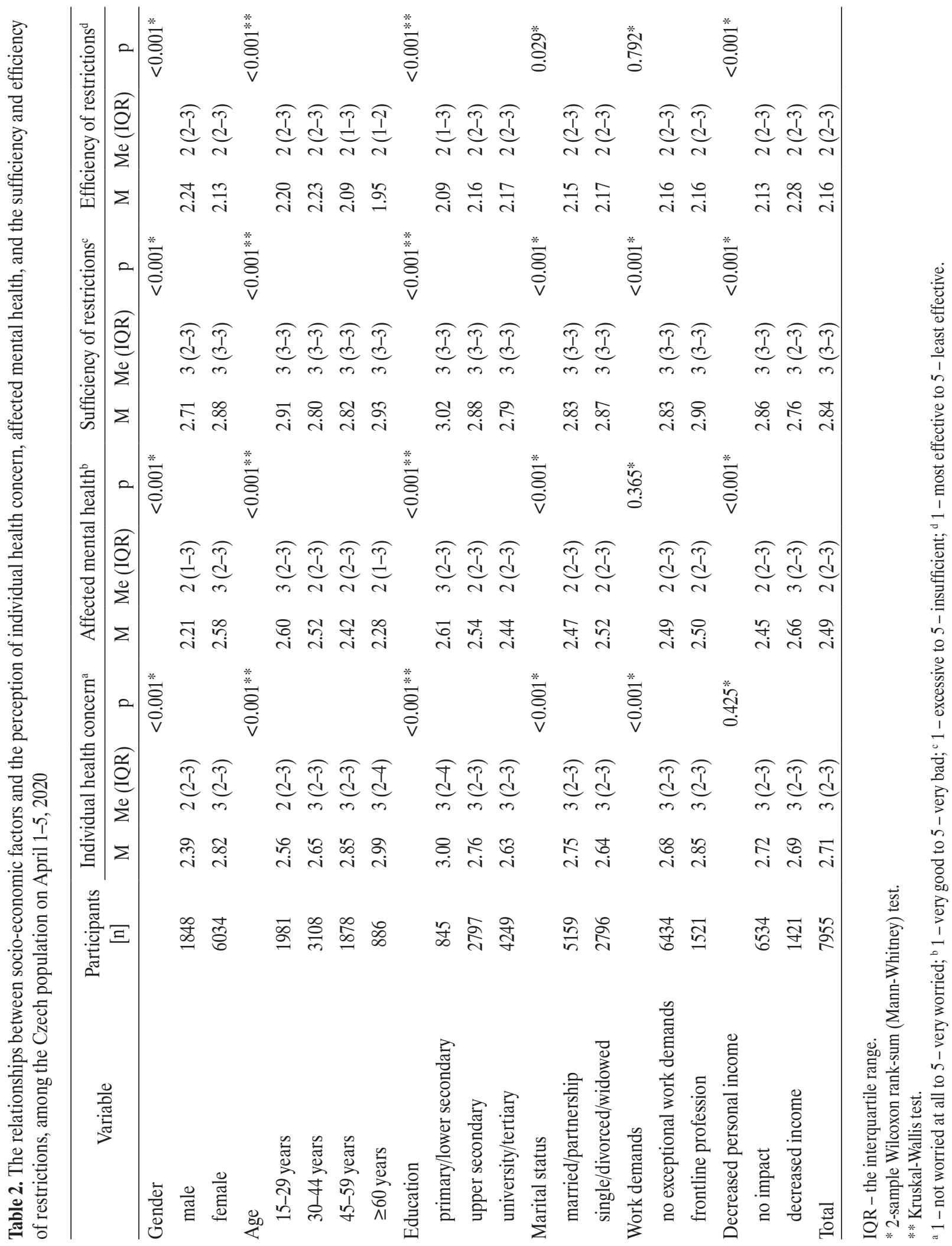




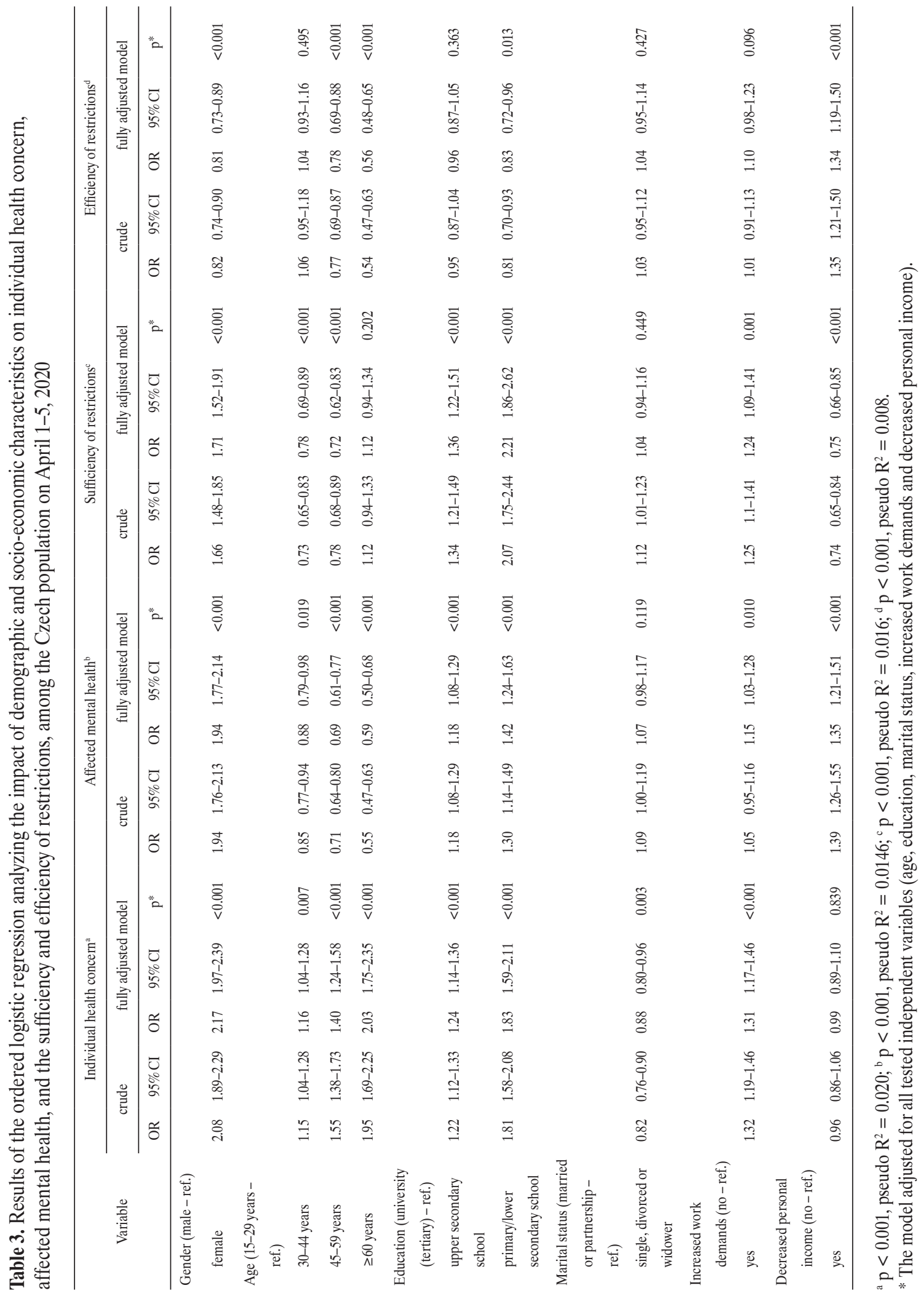


creased during the pandemic, males, younger people aged $<45$ years and people with university education (Table 2). Fully adjusted models were used to identify the socioeconomic variables that predominantly differentiated risk perception (Table 3, Figure 1a). Regarding health concern, females $(\mathrm{OR}=2.17,95 \% \mathrm{CI}: 1.97-2.39)$, people aged $>60$ years $(\mathrm{OR}=2.03,95 \% \mathrm{CI}: 1.75-2.35)$ and loweducated people $(\mathrm{OR}=1.83,95 \% \mathrm{CI}$ : $1.59-2.11)$ worried about their health significantly more than men, the youngest people and highly-educated people, respectively. On the contrary, people living in marriage or partnership worried about their health to a significantly higher extent than singles. The only factor that had no effect on health concern was a decrease in personal income (Table 3).

The impact of socio-economic variables on psychological health in the fully adjusted model was pronounced in both directions (Table 3, Figure 1b). Similar to health concern, the impact on mental health was nearly twice as high in women (OR $=1.94,95 \%$ CI: 1.77-2.14) as in men. The impact of the pandemic on psychological health was found to significantly decrease with age (OR $=0.59,95 \%$ CI: $0.50-0.68$ in the oldest age group). Mental health was more affected in people with the lowest education, and also in people whose personal income had decreased. Surprisingly, no significant difference was found according to the marital status and a slight, but significant, shift was found in people performing frontline professions ( $\mathrm{OR}=1.15,95 \% \mathrm{CI}: 1.03-1.28)$.

The evaluation of the sufficiency of restrictions was not associated with the marital status at all (Table 3, Figure 1c). The implemented restrictions were perceived as significantly more insufficient by women $(\mathrm{OR}=1.71,95 \% \mathrm{CI}$ : $1.52-1.91)$ and people performing frontline professions $(\mathrm{OR}=1.24,95 \% \mathrm{CI}: 1.09-1.41)$ and, on the contrary, as more excessive in the middle-aged groups (30-59 years). The perception of restrictions sufficiency was strongly influenced by the educational level (Table 3, Figure 1c).

The perception of restrictions efficiency brought more consistent results (Table 3, Figure 1d). The socio-economic factors had no significant effect on the perception of restrictions efficiency. A statistically lower efficiency of restrictions was perceived by women $(\mathrm{OR}=0.81,95 \% \mathrm{CI}$ : $0.73-0.89)$, the oldest age group $(\mathrm{OR}=0.56,95 \% \mathrm{CI}$ : 0.48-0.65), and people with the lowest education (Table 3, Figure 1d). A statistically higher efficiency of restrictions was demonstrated in the group whose personal income decreased $(\mathrm{OR}=1.34,95 \% \mathrm{CI}: 1.19-1.50)$.

\section{DISCUSSION}

The study was one of the first studies focusing on the immediate impact of the COVID-19 pandemic on the public health risk perception in the Czech Republic. The Czech government established stricter and long-lasting restrictions in comparison to most western European countries. This study commenced on April 1, 2020, at the time of the massive outbreak of the novel coronavirus disease, which resulted in the launching of the lockdown and related measures. Therefore, this study documented the most critical and strict period of the COVID-19 pandemic in the Czech Republic. The study covered 7966 participants and investigated the individual perception of health concern and psychological impacts of the coronavirus pandemic, while also estimating the people's trust in the efficiency and adequacy of restrictions. Particularly, this work aimed at individual and socio-economic factors influencing the subjective concerns related to the COVID-19 pandemic. Overall, the results of this study show that the public risk perception is significantly affected by multiple individual, psychological and socio-economic factors.

The first research question focused on the individual risk perception related to COVID-19. People were moderately concerned about COVID-19 in terms of being infected. A similar result was also found in a Serbian study whose participants perceived the risk of developing serious health problems (should they be infected) as moderate [19]. At the time of the survey, the outbreak of the disease had been greatly increasing and restrictions were in full 

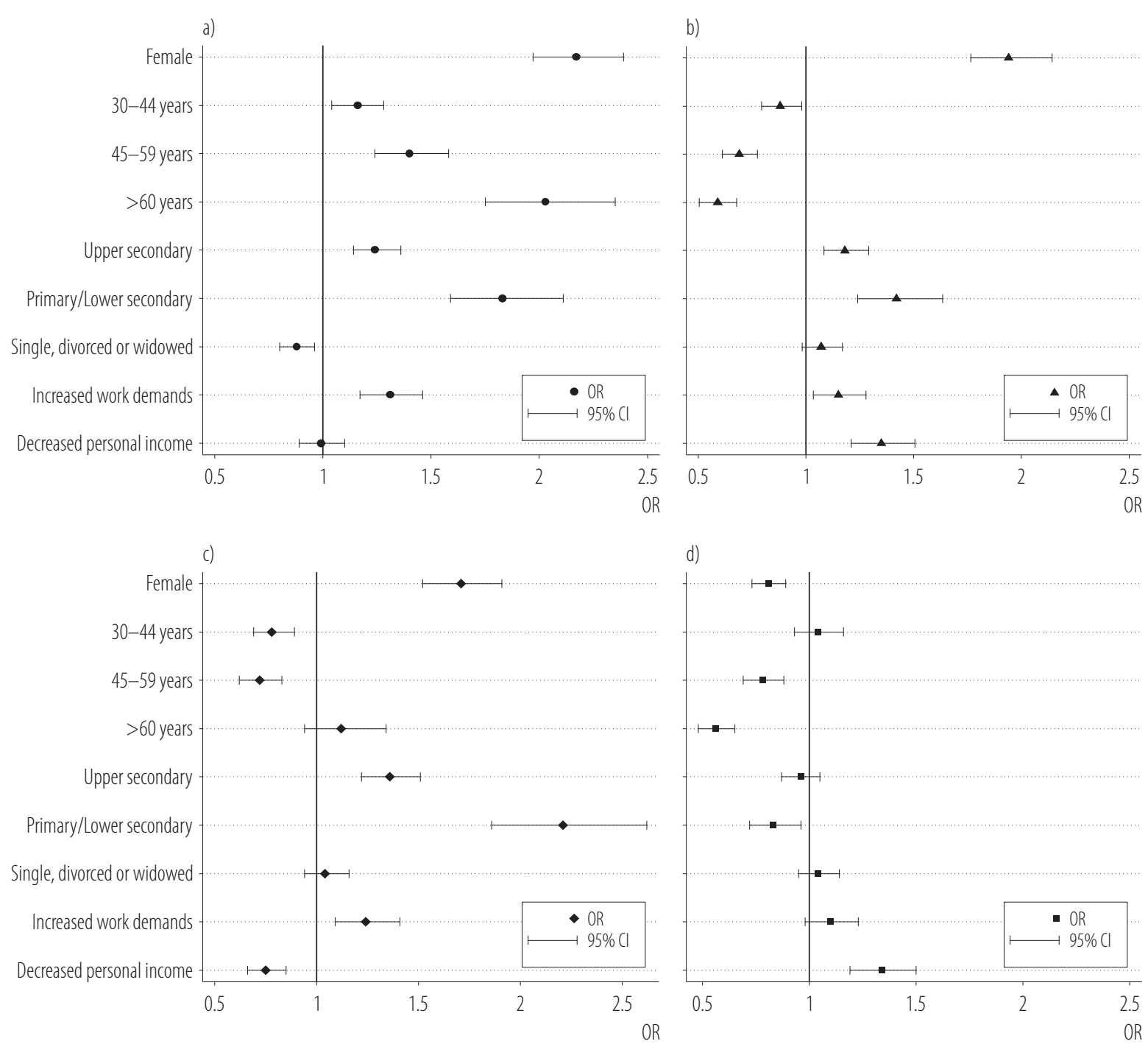

Fully adjusted odds ratio, 1 - baseline.

Figure 1. The impact of demographic and socio-economic characteristics on: a) individual health concern, b) affected mental health, c) sufficiency, and d) efficiency of restrictions, by demographic and socio-economic characteristics, among the Czech population on April 1-5, 2020

force. Nevertheless, compared to other European countries, the prevalence of the disease was substantially lower. Therefore, it is considered that people's risk perception in terms of infectious diseases depends, among other factors, on the severity of the outbreak in their places of residence. This assumption was also confirmed in a recently published study conducted on the Kansas population and a study from the South Korea [20,21].
Significant differences in terms of individual and socioeconomic factors were observed. As regards the most important ones, women, elderly people, low-educated people and people performing frontline professions perceived the health risk related to COVID-19 as significantly worse than others. These findings partially comply with the general assumption that being old, female and low-educated is associated with a higher health concern [22]. This asso- 
ciation was also demonstrated in a study related to the risk perception of the current COVID-19 pandemic in the Israeli population whose oldest age groups ( $>65$ years) perceived a significantly higher personal risk than others [23]. On the other hand, a recent Chinese study showed that younger people were more likely to express the anxiety of being infected in comparison with older people [24].

The other research question related to the risk perception of the psychological impact of the pandemic on the respondents' mental health. Overall, the majority of the respondents perceived their psychological health as good. Similar results were observed in another Chinese study investigating the impact of the COVID-19 pandemic on mental health [17]. These results also show that women, low-educated people, and singles, divorced or widowed people were significantly more sensitive as regards their psychological health. On the contrary, the oldest age group was less likely to be negatively influenced psychologically. These results are comparable with the above-mentioned Chinese study where females were more likely to report a large impact on their mental health, and the mental and social health of people aged $\geq 65$ years was less affected during the COVID-19 pandemic [24].

In addition, the individual perception of the sufficiency and efficiency of measures was explored in the survey. Regarding the survey findings, all measures, except for distinct opening hours in shops reserved for seniors, were perceived as efficient. Frequent hand hygiene, border lockdown and COVID-19 testing were considered as the most effective measures. On the other hand, wearing a face mask was perceived as a less effective measure, as it was supported by $76 \%$ of the survey participants. These results are comparable with the above-mentioned Serbian study whereby washing hands was evaluated as the most effective preventive measure while wearing a face mask was perceived as substantially less protective [19].

Moreover, the results of the rapid questionnaire survey conducted on the UK and U.S. population showed that the participants evaluated wearing a face mask as a less protective measure than other restrictions. On the contrary, a considerable proportion of the respondents demonstrated an overestimated trust in the protective effect of a face mask. Approximately 30-38\% of them agreed with the statement that consistently wearing a face mask reduces the risk of being infected by $>95 \%$ [25], even though the efficacy of surgical or cloth face masks in terms of the transmission of potentially harmful aerosols is considered as only partially effective [26].

\section{Limitations and future research}

This study contains several limitations. Using an onlinebased questionnaire survey is apparently the most crucial factor reducing the involvement of aging and low-educated population in the survey. Even though the survey was also announced by traditional media platforms (national TV and radio), approx. $65 \%$ of the sample consisted of younger respondents aged $<45$ years. The willingness to be engaged in the research study differs based on several demographic factors. Females and highly-educated people are usually more willing to participate in online surveys than male and low-educated people [27]. In this study, no quotas for data stratification by age, gender or education were applied, as a result of which an unequal proportion of the participants was achieved. In particular, women and highly-educated people participated more often than others.

As a matter of fact, the infection risk perception is influenced by both mass and social media, and by social contacts with relatives, friends and colleagues [28]. In this survey, the authors did not explore the communication factors such as the time spent on seeking information as well as the source used to obtain information about the current situation related to COVID-19. Since the outbreak, media reports have been increasingly consumed. Especially young generation have been highly impacted by social media where the users more frequently express their negative emotions, such as anxiety and fear instead of 
positive emotions [29]. Mass media as well as social media, therefore, can play an important role in the psychological and mental health of individuals, especially of those staying isolated due to the lockdown. Therefore, the World Health Organization recommended minimizing the time spent on news feeding. Furthermore, it is considered that the volume of information obtained through legacy and social media may affect the community risk perception and subsequently influence the protective behavior [30].

\section{CONCLUSIONS}

In conclusion, the study findings indicated that women, seniors and low-educated people perceived the COVID-19 risk as more serious than others. The public health risk perception may play a crucial role in the progression of the disease, since the awareness of dealing with COVID-19 is important in limiting the spread of the infection. Therefore, being familiar with the factors influencing public perception and compliance is essential for the pandemic preparedness and planning in the future. On the other hand, it is extremely needed to identify the mentally sensitive groups of people, and to manage the effective and rational risk communication.

The investigation has been continuing during the period of the adopted restrictions which will provide the time-dependent impacts of the mandatory lockdown and related restrictions on public attitudes and behaviors related to COVID-19. Special efforts should focus on the subsequent economic and social consequences of the implemented measures that have a negative impact especially on younger people.

\section{REFERENCES}

1. World Health Organization [Internet]. Geneva: The Organization; 2020 [cited 2020 Aug 3]. Statement on the second meeting of the International Health Regulations (2005) Emergency Committee regarding the outbreak of novel coronavirus (2019-nCoV). Available from: https://www.who.int/newsroom/detail/30-01-2020-statement-on-the-second-meeting- of-the-international-health-regulations-(2005)-emergencycommittee-regarding-the-outbreak-of-novel-coronavirus(2019-ncov).

2. Huang C, Wang Y, Li X, Ren L, Zhao J, Hu Y, et al. Clinical features of patients infected with 2019 novel coronavirus in Wuhan, China. Lancet. 2020;395(10223):497-506, https://doi. org/10.1016/S0140-6736(20)30183-5.

3. Chen J, Peng S, Zhang B, Liu Z, Liu L, Zhang W. An uncommon manifestation of COVID-19 pneumonia on CT scan with small cavities in the lungs: A case report. Medicine (Baltimore). 2020;99(28):e21240, https://doi.org/10.1097/MD.000 0000000021240 .

4. Lai C-C, Shih T-P, Ko W-C, Tang H-J, Hsueh P-R. Severe acute respiratory syndrome coronavirus 2 (SARS-CoV-2) and coronavirus disease-2019 (COVID-19): The epidemic and the challenges. Int J Antimicrob Agents. 2020;55(3):105924, https://doi.org/10.1016/j.ijantimicag.2020.105924.

5. Di Gennaro F, Pizzol D, Marotta C, Antunes M, Racalbuto V, Veronese N, et al. Coronavirus diseases (COVID-19) current status and future perspectives: A narrative review. Int J Environ Res Public Health. 2020;17(8), https://doi.org/10.3390/ ijerph17082690.

6. Adhikari SP, Meng S, Wu Y-J, Mao Y-P, Ye R-X, Wang Q-Z, et al. Epidemiology, causes, clinical manifestation and diagnosis, prevention and control of coronavirus disease (COVID-19) during the early outbreak period: a scoping review. Infect Dis Poverty England. 2020;9(1):29, https://doi.org/10.1186/ s40249-020-00646-x.

7. Khosravi M. Perceived risk of COVID-19 pandemic: The role of public worry and trust. Electron J Gen Med. 2020;17(4):12, https://doi.org/10.29333/ejgm/7856.

8. Eastwood K, Durrheim D, Francis JL, d'Espaignet ET, Duncan S, Islam F, et al. Knowledge about pandemic influenza and compliance with containment measures among Australians. Bull World Health Organ. 2009;87(8):588-94, https:// doi.org/10.2471/blt.08.060772.

9. Jones JH, Salathe M. Early assessment of anxiety and behavioral response to novel swine-origin influenza $\mathrm{A}(\mathrm{H} 1 \mathrm{N1} 1)$. 
PLoS One United States. 2009;4(12):e8032, https://doi.org/ 10.1371/journal.pone.0008032.

10. Bish A, Michie S. Demographic and attitudinal determinants of protective behaviours during a pandemic: A review. Br J Health Psychol. 2010;15(4):797-824, https://doi. org/10.1348/135910710X485826.

11. Blendon RJ, Benson JM, DesRoches CM, Raleigh E, TaylorClark K. The public's response to severe acute respiratory syndrome in Toronto and the United States. Clin Infect Dis United States. 2004;38(7):925-31, https://doi.org/10.1086/382355.

12. Barr M, Raphael B, Taylor M, Stevens G, Jorm L, Giffin M, et al. Pandemic influenza in Australia: using telephone surveys to measure perceptions of threat and willingness to comply. BMC Infect Dis England. 2008;15(8):117, https:// doi.org/10.1186/1471-2334-8-117.

13. Lau JTF, Yang X, Tsui H, Kim JH. Monitoring community responses to the SARS epidemic in Hong Kong: from day 10 to day 62. J Epidemiol Community Health. 2003;57(11):86470, https://doi.org/10.1136/jech.57.11.864.

14. Lau JTF, Yang X, Tsui HY, Pang E. SARS related preventive and risk behaviours practised by Hong Kong-mainland China cross border travellers during the outbreak of the SARS epidemic in Hong Kong. J Epidemiol Community Health England. 2004;58(12):988-96, https://doi.org/10.1136/jech.2003. 017483.

15. Rubin GJ, Amlôt R, Page L, Wessely S. Public perceptions, anxiety, and behaviour change in relation to the swine flu outbreak: cross sectional telephone survey. BMJ. 2009;339: b2651, https://doi.org/10.1136/bmj.b2651.

16. Sood S. Psychological effects of the Coronavirus disease-2019 pandemic [Internet]. Res Humanit Med Educ. 2020;7:23-6 [cited 2020 Aug 29]. Available from: https:// www.rhime.in/ojs/index.php/rhime/article/view/264.

17. Zhang Y, Ma ZF. Impact of the COVID-19 pandemic on mental health and quality of life among local residents in Liaoning Province, China: A cross-sectional study. Int J Environ Res Public Health. 2020;17(7), https://doi.org/10.3390/ ijerph17072381.
18. Van der Weerd W, Timmermans DRM, Beaujean DJMA, Oudhoff J, van Steenbergen JE. Monitoring the level of government trust, risk perception and intention of the general public to adopt protective measures during the influenza A(H1N1) pandemic in the Netherlands. BMC Public Health. 2011;11(1):575, https://doi.org/10.1186/1471-2458-11-575.

19. Cvetković VM, Nikolić N, Nenadić UR, Öcal A, Noji EK, Zečević M. Preparedness and preventive behaviors for a pandemic disaster caused by COVID-19 in Serbia. Int J Environ Res Public Health. 2020;17(11):1-23, https://doi. org/10.3390/ijerph17114124.

20. Geana MV. Kansans in the Middle of the Pandemic: Risk Perception, Knowledge, Compliance with Preventive Measures, and Primary Sources of Information about COVID-19 [Internet]. Kansas J Med. 2020;25(13):160-4 [cited 2020 Aug 30]. Available from: https://pubmed.ncbi.nlm.nih. gov/32612749.

21. Lee M, You M. Psychological and Behavioral Responses in South Korea During the Early Stages of Coronavirus Disease 2019 (COVID-19). Int J Environ Res Public Health MDPI. 2020;17(9):2977, https://doi.org/10.3390/ijerph17092977.

22. Savage I. Demographic influences on risk perceptions. Risk Anal. 1993;13(4):413-20, https://doi.org/10.1111/j.1539-6924. 1993.tb00741.x.

23. Gesser-Edelsburg A, Cohen R, Hijazi R, Abed Elhadi Shahbari N. Analysis of Public Perception of the Israeli Government's Early Emergency Instructions Regarding COVID-19: Online Survey Study. J Med Internet Res. 2020;22(5):e19370, https://doi.org/10.2196/19370.

24. Chan EYY, Huang Z, Lo ESK, Hung KKC, Wong ELY, Wong SYS. Sociodemographic Predictors of Health Risk Perception, Attitude and Behavior Practices Associated with Health-Emergency Disaster Risk Management for Biological Hazards: The Case of COVID-19 Pandemic in Hong Kong, SAR China. Int J Environ Res Public Health MDPI. 2020;17(11):3869, https://doi.org/10.3390/ijerph17113869.

25. Geldsetzer P. Using rapid online surveys to assess perceptions during infectious disease outbreaks: a cross-sectional 
survey on Covid-19. J Med Internet Res. 2020;22(4):e18790, https://doi.org/10.2196/18790.

26. MacIntyre CR, Chughtai AA. A rapid systematic review of the efficacy of face masks and respirators against coronaviruses and other respiratory transmissible viruses for the community, healthcare workers and sick patients. Int J Nurs Stud. 2020;108:103629, https://doi.org/10.1016/j.jinurstu.2020.103629.

27. Smith W. Does Gender Influence Online Survey Participation? A Record-Linkage Analysis of University Faculty Online Survey Response Behavior [Internet]. San José State University; 2008 [cited 2020 Sep 1]. Available from: https:// files.eric.ed.gov/fulltext/ED501717.pdf.

28. Helleringer S, Kohler H-P. Social networks, perceptions of risk, and changing attitudes towards HIV/AIDS: New evidence from a longitudinal study using fixed-effects analysis. Popul Stud (NY). 2005;59(3):265-82, https://doi.org/ $10.1080 / 00324720500212230$.

29. Song J, Song TM, Seo D-C, Jin D-L, Kim JS. Social Big Data Analysis of Information Spread and Perceived Infection Risk During the 2015 Middle East Respiratory Syndrome Outbreak in South Korea. Cyberpsychology Behav Soc Netw. 2017;20(1):22-9, https://doi.org/10.1089/cyber.2016.0126.

30. Chan MS, Winneg K, Hawkins L, Farhadloo M, Jamieson KH, Albarracín D. Legacy and social media respectively influence risk perceptions and protective behaviors during emerging health threats: A multi-wave analysis of communications on Zika virus cases. Soc Sci Med. 2018;212:50-9, https://doi.org/10.1016/j.socscimed.2018.07.007.

This work is available in Open Access model and licensed under a Creative Commons Attribution-NonCommercial 3.0 Poland License - http://creativecommons.org/ licenses/by-nc/3.0/pl/deed.en. 